Revista Tecné, Episteme y Didaxis: TED. Año 2014, Número Extraordinario. ISSN Impreso: 0121-3814, ISSN web: 2323-0126 Memorias, Sexto Congreso Internacional sobre Formación de Profesores de Ciencias. 08 al 10 de octubre de 2014, Bogotá

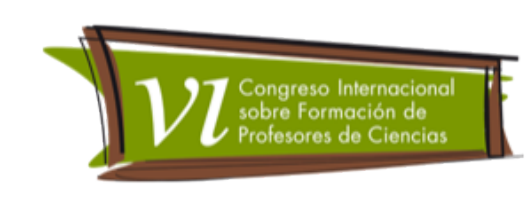

\title{
Os Três Momentos Pedagógicos no estudo da Dengue para a Educação de Jovens e Adultos: um diálogo possível
}

Oliveira, Leandro Gonçalves'; Lyra, Daniella Galiza Gama²; Barrio, Juan Bernardino Marques ${ }^{3}$

Categoria 2. Trabalhos de investigação

\section{Resumo}

Os Três Momentos Pedagógicos (3MP) foram utilizados como estratégia de ensino visando a aprendizagem com significado social de temas científicos, no caso, a Dengue. Os sujeitos foram alunos das $5^{a}$ e $6^{a}$ séries do ensino fundamental da Educação de Jovens e Adultos (EJA) de duas escolas da Rede Municipal de Educação de Goiânia. As análises das gravações das aulas e das respostas de um questionário revelaram as seguintes categorias de análise: Curiosidade ingênua e epistemológica; [Re]Construção conceitual: do ingênuo para o científico; e $\bigcirc$ papel da problematização: conscientização e dialogicidade. Os resultados demonstram que o ensino na EJA, pautado na problematização freireana e nos $3 \mathrm{MP}$, se configura como uma estratégia de aprendizagem para esta modalidade de ensino.

\section{Palavras-chave}

Educação de Jovens e Adultos; Três Momentos Pedagógicos; Educação Libertadora; Dengue.

\section{Objetivo}

Embora a Educação de Jovens e Adultos (EJA) venha conquistando seu espaço no cenário educativo atual é uma prática histórica que remonta ao período colonial brasileiro que foi se revelando de interesse estratégico do capital, construindo-se e

\footnotetext{
1 Pós-Graduação em Educação em Ciências e Matemática (MECM)-UFG. lego@ufg.br

2 MECM/UFG. danygaliza@yahoo.com.br

3 MECM/UFG. juanbmb@hotmail.com
} 
Revista Tecné, Episteme y Didaxis: TED. Año 2014, Número Extraordinario. ISSN Impreso: 0121-3814, ISSN web: 2323-0126 Memorias, Sexto Congreso Internacional sobre Formación de Profesores de Ciencias. 08 al 10 de octubre de 2014, Bogotá

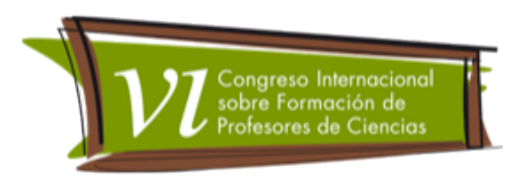

reconstruindo-se sobre várias vertentes e vários olhares. Falar de EJA sem tratar de Paulo Freire é praticamente impossível, uma vez que sua proposta de alfabetização se baseia no diálogo e leva em consideração a realidade dos educandos, especialmente adultos que possuem uma cultura adquirida ao longo da vida.

O presente trabalho se desenvolveu em duas escolas pertencentes à Secretaria Municipal de Educação de Goiânia e considerando os aspectos que permeiam esta modalidade de ensino e a ação da pesquisadora/professora de Ciências na EJA surgiu a pergunta: qual é a contribuição dos Três Momentos Pedagógicos para o ensino em Ciências ao se trabalhar com a EJA? Diante desta pergunta, o objetivo deste trabalho foi avaliar a contribuição dos 3MP no ensino de Ciências (Dengue) para a EJA.

\section{Marco teórico}

A proposta de alfabetização para adultos de Paulo Freire parte de uma investigação inicial, onde aluno e professor buscam palavras e temas centrais (palavras geradoras), que fazem parte do cotidiano do educando, para iniciar a alfabetização. Depois viria a etapa da tematização, na qual os sujeitos envolvidos no processo codificam e decodificam as palavras/temas levantados a fim de buscar um significado social para eles, tomando consciência do mundo ao redor. E, posteriormente, na etapa da problematização, educando e educador substituem a visão inicial "mágica" do mundo por uma visão crítica, partindo para transformar o contexto vivido.

Para o educador comprometido com a prática problematizadora, o conteúdo a ser trabalhado com os alunos nada mais é do que a restituição sistematizada, organizada e enriquecida ao educando daqueles elementos que lhes foram entregues de forma desordenada.

Para o educador-educando, dialógico, problematizador, o conteúdo programático da educação não é uma doação ou uma imposição - um conjunto de informes a ser depositado nos educandos - mas a devolução organizada, sistematizada e acrescentada ao povo, daqueles elementos que este the entregou de forma inestruturada (Freire, 2005, pág.98). 
Revista Tecné, Episteme y Didaxis: TED. Año 2014, Número Extraordinario. ISSN Impreso: 0121-3814, ISSN web: 2323-0126 Memorias, Sexto Congreso Internacional sobre Formación de Profesores de Ciencias. 08 al 10 de octubre de 2014, Bogotá

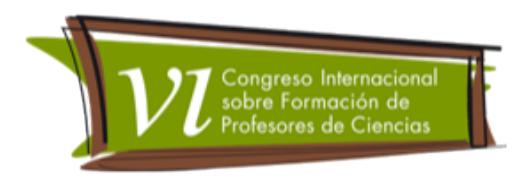

Tendo como ponto de partida as situações reais, atuais, concretas e refletindo desejos da comunidade, o conteúdo programático deve ser organizado e compreendido como resultado da práxis educativa, através da qual o indivíduo torna-se capaz de modificar sua realidade (Gadotti, 1991, pág. 65). O que será trabalhado pode ser proposto aos educandos partindo de contradições básicas, situações reais e existenciais dos mesmos. Jamais conteúdos que nada ou pouco se relacionem com suas aspirações, pois assim ficam vazios e sem sentido, voltando a incorrer na educação bancária.

Então, partindo das ideias propostas por Freire, Delizoicov, Angotti e Pernambuco (2002) estabelecem posturas e encaminhamentos, especialmente no que diz respeito à Educação em Ciências, de forma que:

A abordagem temática é uma perspectiva curricular cuja lógica de organização é estruturada com base em temas, com os quais são selecionados os conteúdos de ensino das disciplinas. Nessa abordagem, a conceituação científica da programação é subordinada ao tema (Delizoicov et al., 2002, pág.189).

Com base na dialogicidade proposta por Freire (2005 e 2010), desenvolveu-se uma metodologia ou estratégia didática conhecida como "Três Momentos Pedagógicos (3MP)" que consiste em:

1. Problematização Inicial: Caracterizado pela compreensão e apreensão da posição dos alunos frente ao assunto, é desejável que a postura do professor seja mais de questionar e lançar dúvidas do que de responder e fornecer explicações (Delizoicov \& Angotti, 2000, pág. 54-55).

2. Organização do Conhecimento: Inicia-se com o estudo sistemático do conteúdo programático na qual a "estrutura profunda" da codificação pode ser apreendida. É o momento de análise dos fatos procurando superar a visão sincrética e eminentemente descritiva, até então exposta (Delizoicov, 1982, pág.150).

3. Aplicação do Conhecimento: Destina-se, sobretudo, a abordar sistematicamente o conhecimento que vem sendo incorporado pelo aluno, para analisar e interpretar 
Revista Tecné, Episteme y Didaxis: TED. Año 2014, Número Extraordinario. ISSN Impreso: 0121-3814, ISSN web: 2323-0126 Memorias, Sexto Congreso Internacional sobre Formación de Profesores de Ciencias. 08 al 10 de octubre de 2014, Bogotá

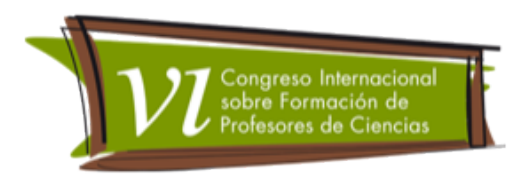

tanto as situações iniciais que determinaram o seu estudo, como outras situações que não estejam diretamente ligadas ao motivo inicial, mas que são explicadas pelo mesmo conhecimento (Delizoicov \& Angotti, 2000, pág. 55).

Na EJA, a dinâmica dos 3MP e a proposta de Freire vão de encontro à valorização do conhecimento do aluno, buscando um posicionamento crítico ante sua realidade, a fim de compreendê-la e, de alguma forma, modificá-la. Assim, a problematização deve ser um processo no qual o aluno vai desestabilizar seu conhecimento anterior, ao se confrontar com determinadas situações cotidianas e sentirá falta do que não sabe. Dessa forma, a experiência de vida do educando é o ponto de partida de uma educação que considera que seu contexto de vida pode ser apreendido e modificado (Delizoicov, 1983, pág. 56).

\section{Metodologia}

Esta pesquisa se encaixa nos padrões de abordagem da pesquisa qualitativa, uma vez que a análise de dados primou por compreender o comportamento das experiências humanas através dos 3MP. Além disso, a pesquisa "envolve a obtenção de dados descritivos, obtidos pelo contato direto do pesquisador com a situação estudada, enfatiza mais o processo que o produto e se preocupa em retratar a perspectiva dos participantes" (Lüdke e André, 2013, pág. 87).

Os locais escolhidos para desenvolver o trabalho foram duas escolas municipais que se localizam na região norte de Goiânia, Goiás, Brasil. Em tais escolas, são oferecidas a EJA, no período noturno, e optou-se por trabalhar com os alunos que estão cursando a $5^{a}$ e a $6^{a}$ séries, uma vez que a escola comporta as duas turmas juntas num mesmo espaço físico, além de que o conteúdo em questão, a Dengue, está contido na matriz curricular de tais séries.

Durante as aulas ministradas nas referidas escolas (Escola Municipal 1 - EM1 - e Escola Municipal 2 - EM2), ao tratar do conteúdo de Vírus com os alunos da EJA (identificados como A quando estudantes da Escola Municipal 1 e B quando estudantes da Escola Municipal 2), fala-se sobre as doenças virais quando surgiu uma série de dúvidas sobre a Dengue. Assim, optou-se por este assunto para trabalharmos os 3MP. 
Revista Tecné, Episteme y Didaxis: TED. Año 2014, Número Extraordinario. ISSN Impreso: 0121-3814, ISSN web: 2323-0126

Memorias, Sexto Congreso Internacional sobre Formación de Profesores de Ciencias. 08 al 10 de octubre de 2014, Bogotá

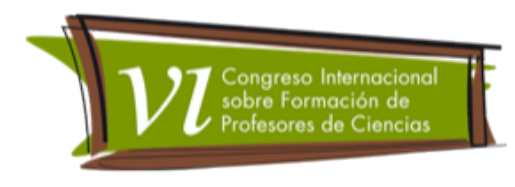

No que se refere ao primeiro Momento Pedagógico, foram distribuídos textos aos alunos sobre a Dengue, incluindo um do ano de 1942 e outros atuais. Também foi exibido um vídeo sobre o ciclo reprodutivo do vetor da Dengue, a fim de realizar a problematização. Ao final desta etapa, os alunos escreveram questões que, posteriormente, seriam respondidas. O segundo momento foi marcado por aulas teóricas referentes aos insetos, vetores da Dengue. No terceiro, foi aplicado um questionário visando verificar a possível apreensão dos conceitos e assuntos estudados, no intuito de que eles conseguissem identificar situações cotidianas que pudessem aplicar os conhecimentos adquiridos ao longo das aulas.

\section{Resultados}

Os instrumentos de coleta de dados foram elaborados a priori, e destes, a partir das falas dos alunos, emergem a posteriori as categorias de análise:

1. Curiosidade ingênua e epistemológica - a partir do conhecimento dos alunos acerca do tema, mostram sua vontade de conhecer mais da temática em questão e se a mesma é ou não relevante para eles.

2. [Re]construção conceitual: do ingênuo para o científico - tem como base a reestruturação do conhecimento dos alunos partindo de um conhecimento de senso comum e estrutura-se em um conhecimento mais elaborado.

3. O papel da problematização: conscientização e dialogicidade - os alunos extrapolam os conhecimentos para além da sala de aula, exprimindo opiniões, enriquecendo o conteúdo com exemplos da vida prática e procurando incorporar os conhecimentos adquiridos na escola ao cotidiano.

As falas e respostas dos alunos foram analisadas à luz das categorias e é possível perceber como os 3MP contribuíram para a participação dos alunos e aprendizado, conforme apresentado abaixo.

Tem as asinhas, as perninhas, todas de risquinhas... (A7)

Essa é a fêmea né? Ela é geralmente é maior. (A 10) 
Revista Tecné, Episteme y Didaxis: TED. Año 2014, Número Extraordinario. ISSN Impreso: 0121-3814, ISSN web: 2323-0126

Memorias, Sexto Congreso Internacional sobre Formación de Profesores de Ciencias. 08 al 10 de octubre de 2014, Bogotá

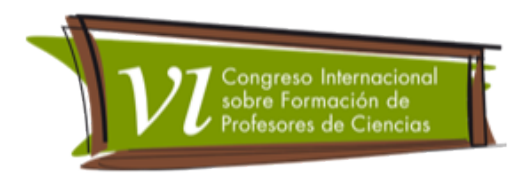

No prazo de três dias ele vira larva (B5)

Estes exemplos mostram que a curiosidade quanto à forma e ao modo de reprodução do agente transmissor da Dengue estão presentes nos alunos e, mesmo que eles não saibam cientificamente identificar as estruturas dos insetos, conseguem diferenciar suas partes, sexo e informações referentes ao ciclo reprodutivo do vetor.

Torna-se visível, através das falas dos estudantes que, ao longo da aula, os próprios alunos foram sistematizando o conhecimento adquirido e substituindo a linguagem comum pelos termos científicos aprendidos.

Quando o animal não tem osso, ele é chamado de invertebrado. (A2)

Na verdade, a casquinha da cigarra professora é um tipo de esqueleto. Ou pelo menos, tem a função de proteger os órgãos dela né? (A10).

A boca do mosquito Aedes precisa funcionar como uma agulha, senão ele não consegue chupa o sangue da gente professora. Desses todos, o aparelho picador que deve ser desse danado. (A3)

Engraçado que a abelha come aquele pozinho amarelo da flor, então ela não pode ter essa boca picadora. Mas então a abelha não pica. (A7)

Também é interessante observar que o estudante consegue internalizar de tal forma 0 novo conhecimento adquirido, que eles mesmos, ao apresentar um termo incorreto, se corrigem.

É possível perceber, especialmente durante o terceiro momento, as atitudes "libertadoras" observadas em alguns momentos das aulas e através das falas como as que se seguem.

É melhor contaminar com o exemplo do que com a doença. (A9)

A população tem que ter paciência. Se todos fizer sua parte não acontecia isso. (A3)

Temática 1. Enfoque CTS: Alfabetización científica y Cuestiones socio científicas 
Revista Tecné, Episteme y Didaxis: TED. Año 2014, Número Extraordinario. ISSN Impreso: 0121-3814, ISSN web: 2323-0126 Memorias, Sexto Congreso Internacional sobre Formación de Profesores de Ciencias. 08 al 10 de octubre de 2014, Bogotá

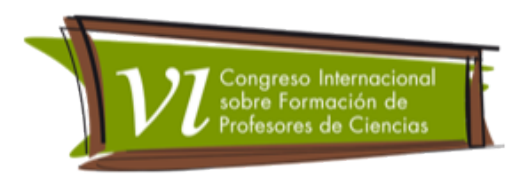

Tinha que arrumar um jeito de combater isso aí enquanto é larva ainda não é professora? (B3)

Dá pra aprender coisas que não sabemos sobre o mosquito e a melhor forma de combater ele né professora. Afinal, vemos casos de Dengue todo dia e todo ano na $\mathrm{TV}$, no jornal e na vizinhança da casa da gente. (B7)

Essas declarações dos estudantes, e tantas outras que não cabem neste artigo, ao término da aula, mostram que o fato de aprender conteúdos que envolvem o seu cotidiano é interessante e, por isso, Ihes desperta expectativas quanto ao estudo de Ciências (Delizoicov, 2001, pág. 82).

Existiu uma certa dificuldade em avaliar o conhecimento de senso comum que os alunos possuem com o conhecimento científico. Mas essa mudança pode ser sentida em algumas falas dos alunos, conforme as descritas a seguir.

Então, se ela pega sangue, ela tem a boca do tipo picador. (B6).

Ah, então em cidades quentes, como o Rio de Janeiro, tem mais casos porque o mosquito se reproduz mais rápido. A chance dele picar gente contaminada é maior. (B9).

Então o mosquito só carrega um vírus de cada vez dentro do corpo, porque aquele vírus que vai conseguir crescer no corpo do mosquito e não deixa outros crescerem. (B3)

Em todos os momentos é fundamental a postura dialógica do professor para que os estudantes sintam-se à vontade e livres para apresentar suas ideias, já que assim, eles participam mais ativamente das aulas, evidenciando a dinamicidade dos Momentos e que se permeiam durante o desenvolvimento de todo este trabalho.

\section{Conclusões}

Diante da análise das aulas, da fala dos alunos e das respostas dos questionários, pôde-se avaliar que os 3MP apresentaram-se como uma boa estratégia de ensino no 
Revista Tecné, Episteme y Didaxis: TED. Año 2014, Número Extraordinario. ISSN Impreso: 0121-3814, ISSN web: 2323-0126 Memorias, Sexto Congreso Internacional sobre Formación de Profesores de Ciencias. 08 al 10 de octubre de 2014, Bogotá

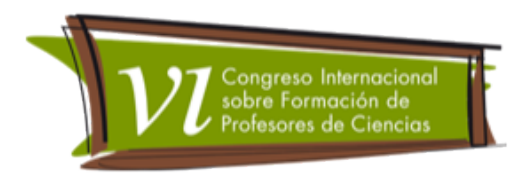

trabalho com EJA. A primeira categoria revelou o fato dos alunos apresentarem uma cultura adquira ao longo da vida, a qual pode se mostrar como ponto de partida no trabalho com temas científicos; a categoria 2 proporcionou uma postura dialógica, pois os estudantes sentiram-se mais livre contribuir e participar das aulas, sem medo de errar; e, a terceira categoria propiciou encontrar relações entre o conteúdo e suas vidas cotidianas, facilitando a aprendizagem e aumentando o interesse no conteúdo escolar. Embora não tenhamos objetivado o enfoque CTSA, o mesmo foi revelado de maneira explícita, a partir do momento em que os alunos conseguiram estabelecer a relação entre o conhecimento científico e seu cotidiano, conforme explicitado nas transcrições contidas na categoria 3 acima descrita.

\section{Referências bibliográficas}

Delizoicov, D. (1982). Concepção problematizadora para o ensino de ciências na educação formal. Dissertação de Mestrado, Universidade de São Paulo, São Paulo, SP, Brasil.

Delizoicov, D.. (1983). Ensino de física e a concepção freireana de educação. Revista Ensino de Física, 5(2), 85-98.

Delizoicov, D.. (2001). Problemas e Problematizações. In: M. Pietrocola (Org.). Ensino de física: conteúdo, metodologia e epistemologia numa concepção integradora. Florianópolis, SC: UFSC.

Delizoicov, D., \& Angotti, J. A. (2000). Metodologia do ensino de ciências. São Paulo: Cortez.

Delizoicov, D., Angotti, J. A., \& Pernambuco, M. M. (2002). Ensino de ciências: fundamentos e métodos. São Paulo: Cortez.

Freire, P. (2005). Pedagogia do oprimido. Rio de Janeiro: Paz e Terra.

Freire, P. (2010). Pedagogia da autonomia - Saberes necessários à prática educativa. São Paulo: Paz e Terra. 
Revista Tecné, Episteme y Didaxis: TED. Año 2014, Número Extraordinario. ISSN Impreso: 0121-3814, ISSN web: 2323-0126 Memorias, Sexto Congreso Internacional sobre Formación de Profesores de Ciencias. 08 al 10 de octubre de 2014, Bogotá

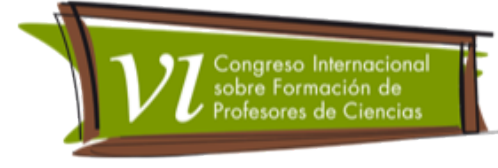

Gadotti, M. (1991). Convite a leitura de Paulo Freire. São Paulo: Scipione.

Lüdke, M., \& André, M. (2013). Pesquisa em educação: abordagens qualitativas. $2^{a}$ ed. São Paulo: EPU. 